\title{
Usability Context Analysis for Virtual Reality Training in South African Mines
}

\author{
Etienne van Wyk \\ ICT Faculty \\ Tshwane University of Technology \\ Private Bag X680, Pretoria, 0001 \\ South Africa \\ +27123825558 \\ vanwykea@tut.ac.za
}

\author{
Ruth de Villiers \\ School of Computing \\ University of South Africa \\ P O Box 392, Unisa, 0003, \\ South Africa \\ +27124296559 \\ dvillmr@unisa.ac.za
}

\begin{abstract}
The usability of any tool or system has to be viewed in terms of the context in which it is used, and its appropriateness to that context. According to the ISO definition of usability, the context of use includes the users, tasks, equipment (hardware, software and materials), and the physical and social environments in which a product is used. Context analysis provides a framework to ensure that all factors which may affect the usability of a product are considered.
\end{abstract}

Safety in the South African mining industry is a vital issue. On average, one worker dies every working day, and about 16 are injured in mine-related accidents. Inadequate or insufficient training is often cited as a root cause for many mining fatalities. However, training outside the direct working environment provides only limited real-life opportunities and may fail to make a significant impact within the tense working environment itself. Virtual reality-based training tools can, by contrast, provide simulated exposure to real-world working conditions without the associated risks.

This paper discusses contextual analysis for virtual reality (VR) application development, applied to safety training in mines. This contextual analysis has been conducted to contribute to the usability of future system design. It also provides a basis for designing subsequent usability evaluations. The results of the context analysis were applied to the design of a prototype, which was used and evaluated at two large platinum mines.

\section{Categories and Subject Descriptors}

H.5.1 [Information Interfaces and Presentation]: Multimedia Information Systems - Artificial, augmented, and virtual realities;

K.3.1 [Computers and Education]: Computer Uses in Education - computer-assisted instruction.

\section{General Terms}

Measurement, Design, Human Factors.

Permission to make digital or hard copies of all or part of this work for personal or classroom use is granted without fee provided that copies are not made or distributed for profit or commercial advantage and that copies bear this notice and the full citation on the first page. To copy otherwise, to republish, to post on servers or to redistribute to lists, requires prior specific permission and/or a fee.

SAICSIT 2008, 6 - 8 October 2008, Wilderness Beach Hotel, Wilderness, South Africa Copyright $(2008$ ACM 978-1-60558-286-3/08/10 ...\$5.00

\section{Keywords}

Context Analysis, context of use, e-training, safety training, usability, virtual reality.

\section{INTRODUCTION}

Usability is a general quality of the appropriateness to a purpose of an artefact [Brooke, 1998]. This means the usability of any tool or system has to be viewed in terms of the context in which it is used, and its appropriateness to that context. The International Organisation for Standardisation defines usability as the "extent to which a product can be used by specified users to achieve specified goals with effectiveness, efficiency and satisfaction in a specified context of use" [ISO, 1997]. The context of use includes the users, tasks, equipment (hardware, software and materials), and the physical and social environments in which a product is used.

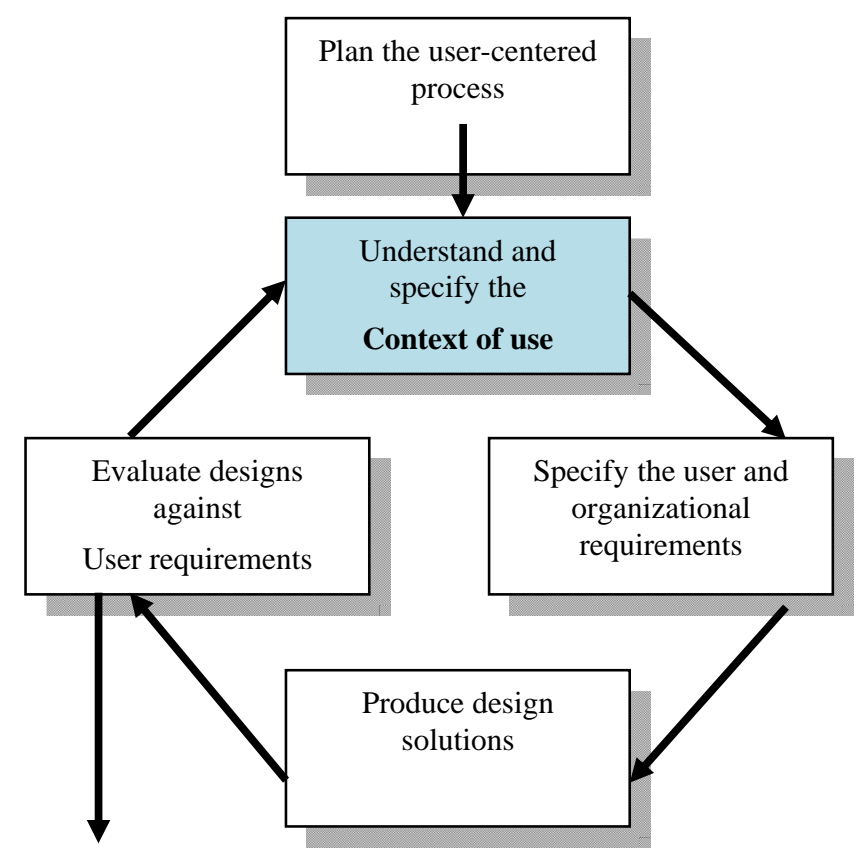

Meet requirements

Figure 1: The human-centred design cycle (from ISO 13407). 
In general, it is impossible to specify the usability of a system without first defining who are the intended users of the system, the tasks those users will perform with it, and the characteristics of the physical, organisational and social environment in which it will be used.

Context of use is also incorporated into the ISO 13407 standard on human-centred design [ISO, 1999]. This defines the process of understanding and specifying the context of use as one of the main stages within the human-centred design process (see Figure 1). Preece, Rogers and Sharp [2007] refer to context of use as relating to four aspects of environmental requirements, namely: the physical, social, organizational and technical environments, all of which are implicitly or explicitly addressed in this paper.

Usability Context Analysis (UCA) is a structured method for eliciting detailed information about a product and how it will be used, and for deriving a plan for a user based evaluation of a product. For this method stakeholders meet to detail the actual circumstances (or intended use) of a product [Bevan, 1997]. In this study, the methodology of UCA is extended to include all the context-of-use aspects of the ISO 9241 usability framework (see Figure 2).
Usability context analysis provides a framework to ensure that all factors which may affect the usability of a product are considered. This paper discusses contextual analysis in virtual reality application development, applied to the case of mine safety training. This contextual analysis has been conducted to contribute to the usability of system designs in the future. It also provides a basis for designing later usability tests.

The study described in this paper aims to guide the development of future VR training systems. It aims to answer a number of questions about the real-life tasks and the context that these systems should support, functionality of such a system and its level of immersion. For this purpose, the following research questions were stated:

1. What are the contextual requirements and constraints for VR training systems for the mining industry?

2. What type of VR environment would be most suitable in this context?

3. What is the general suitability and potential of virtual reality technology for training applications in the field of mine safety training?

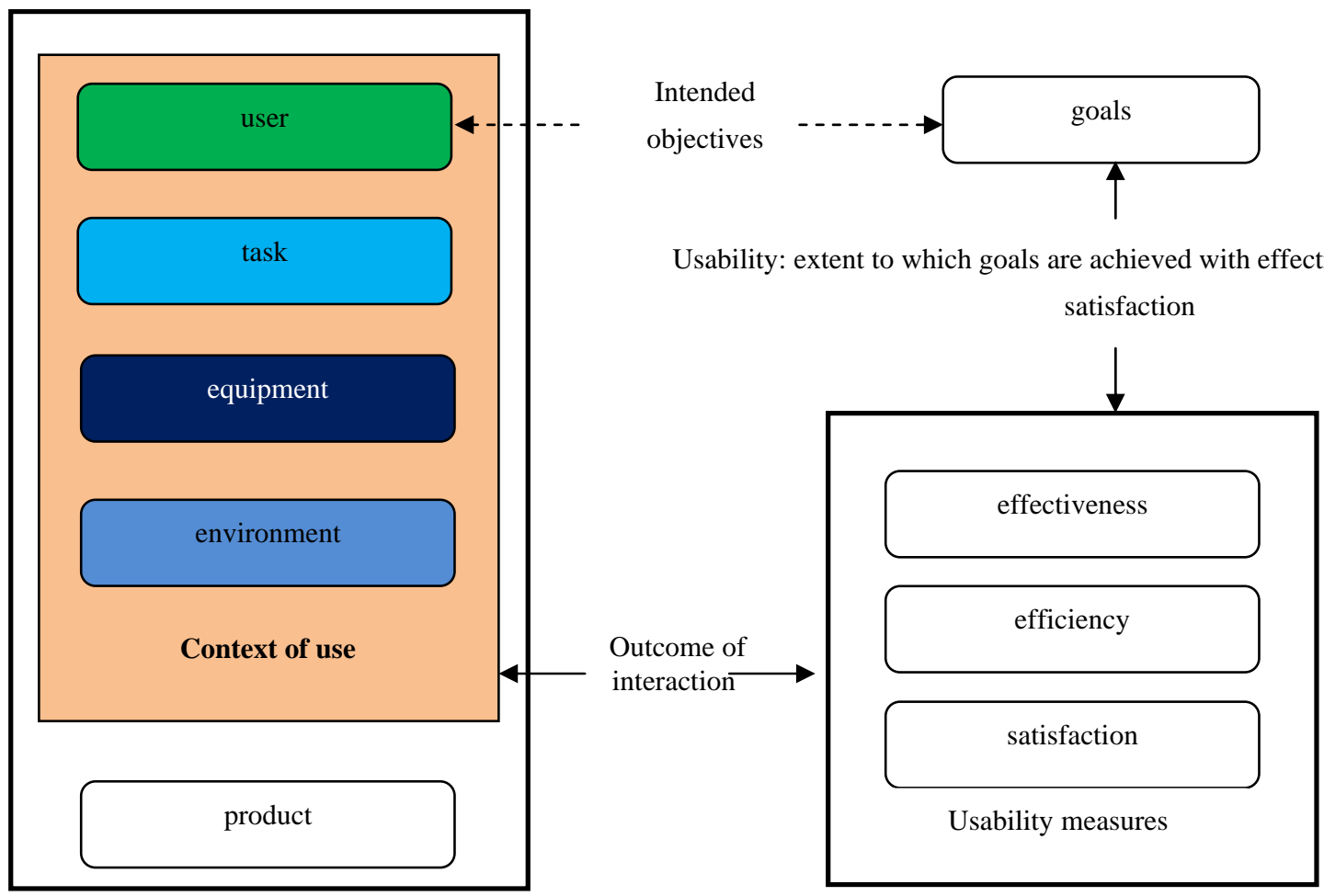

Figure 2: Usability framework (from ISO 9241)

\section{SAFETY IN THE MINING INDUSTRY}

On average, one worker dies in the South African mining industry every working day, and about 16 are injured in minerelated accidents [Business Day, 2002].

Safety performance data for South African mines is published by the Mine Health and Safety Inspectorate. There were 3808 underground reportable injuries in 2003, and 446 surface reportable injuries. In total, 264 people died in mining accidents in 2003, with 293 and 288 fatalities in 2002 and 2001 respectively. The Inspectorate also lists major accidents where four or more people were killed. There has been an average of seven such major mining accidents a year over the last 20 years [Department of Minerals and Energy, 2007]. 
In their Annual Report for 2004 the South African Chamber of Mines states that the industry safety target is "zero rate of fatalities and injuries" and a milestone is set for 2013 to achieve constant and continuous improvement "equivalent to current international benchmarks, at the least”. All the stakeholders share the view that safety performance must be improved, and that "even one fatality is one too many" [Chamber of Mines, 2004:107]. The South African mining industry also participated in the drafting of the International Labour Organisation's Convention 176 (Safety and Health in Mines) in 1995, and the South African government ratified the convention in June 2000 [Mining Weekly, 2002].

Whilst employers are primarily responsible for providing safe and healthy workplaces, the Department of Minerals and Energy is the lead agent in promoting, monitoring and enforcing legislation and initiating prosecution in terms of the Mine Health and Safety Act of 1996. Guidelines regarding the enforcement of the Act were released in January 2005 by the South African Government. This document contains instructions enforcing compliance with any provisions of the Act and makes provision for fines and prosecution of offenders [Department of Minerals and Energy, 2006].

Unfortunately, while new training rules and regulations have been enacted, many training tools and techniques are not as effective as they could be in providing safety training. Recent meetings of Safety, Health and Environment managers at South African mines indicate that the mining community needs improved training tools [Baker, 2005; Moldenhauer, 2004; Wenhold, 2005]. During interviews conducted at two large South African mines, the mine managers specifically requested help in developing new safety training methods. They mentioned the importance of effective training and the need for improved and updated mine safety training material [Lubbe, 2006; Stander, 2005].

Research into reducing subsurface mining accidents has traditionally focused on reducing fall-of-ground accidents by providing improved support units and systems and improved mining layout design [Squelch, 2000]. An additional approach promoted in the Mine Health \& Safety Act 29 of 1996 is, however, to improve the level and effectiveness of training given to underground workers. In the context of underground accidents this training emphasis lies in the area of hazard identification and associated remedial safety action.

\section{VIRTUAL REALITY TRAINING IN INDUSTRY}

Inadequate or insufficient training is often cited as a root cause for many mining fatalities [Orr, Filigenzi \& Ruff, 2002]. Training outside the direct working environment provides only limited real-life opportunities. As a result, such training may fail to make a significant impact in the tense working environment itself. Virtual Reality-based training tools, however, can provide a basis for workers to enter their working conditions without the associated risks.

Virtual reality, popularly referred to as VR, is a rapidly growing technology which utilizes the ever-increasing power of computing to simulate real world and imaginary environments and situations with a high degree of realism and interactiveness. Users can interact with the virtual worlds via a variety of hardware devices (e.g. joysticks and gloves). The impression of actually being in the virtual world (immersion) can be created and enhanced by special optical and audio devices (e.g. headmounted displays and 3D sound).

VR is currently being used and investigated for providing training solutions in a variety of industries and fields such as military, medical, power generation and aircraft [Van Wyk, 2006]. VR has a number of features that appear well suited to training for a mining environment and, in particular, for hazard recognition and associated remedial safety action. The primary features of relevance are: the ability to expose trainees to simulated hazardous situations without putting them in any actual danger; the facility to simulate hazardous situations more frequently than would be encountered in the real world; and the simulation of situations that have not previously occurred but which could be encountered in the industry.

Virtual Reality has evolved considerably over the last two decades. "Although VR is still maturing as a technology, implications for its future as a tool for education, science, medicine and other fields, seem certain” [De Strulle, 2004:76]. The goal of this research project is to explore the design and development of cost-effective virtual mine environments. These environments can be used to train underground mine workers in hazard recognition and correct safety procedures. Three categories of VR often used are non-immersive or desktop, semi-immersive and immersive VR. For this study immersive systems are considered as CAVElike systems and head-mounted displays. Semi-immersive systems are other stereoscopic visualisations and projections. Non-immersive systems are nonstereoscopic VR applications offering 3D simulation and visualisation.

Current training methods used in mines rely mainly on repetitive classroom style learning, with some instruction being given in a physical mock-up of an underground workplace followed by on-the-job training. However, under classroom conditions, workers do not make safety decisions under the same conditions of stress that they would experience underground. As a result, depending on the stress levels of the real working environment, the decisions that are taken in the authentic environment underground may differ significantly from those taken under more relaxed circumstances. Another important factor is that the actual underground environment is dark and visibility is often limited to the available light from cap lamps. To enhance the effectiveness of training, an alternative training design is required that simulates the real threats as closely as possible.

\section{LITERATURE STUDY}

Limited research has been published on usability context analysis in VR. Maguire [2001] states that "when assessing a product from a Human Factors point of view, there is a tendency to forget about the Context of Use". Information Technology products are often divided into those which are usable and have ergonomic features and those which are not. It is argued that it is incorrect to describe a product as ergonomic or usable, without also describing the context in which the product will be used. Such context analysis, also called Usability Context Analysis (UCA), includes whom the product was designed for, what it will be used for and where it will be used. 
Maguire also proposes a process for performing a context analysis. The method described is particularly aimed at nonexperts in the area of user-centered design and evaluation. This process was applied to an Automatic Teller Machine example, where it was highlighted that reconciling technical and business requirements with user requirements remains an important issue. The article stresses that the advantage of applying context-ofuse analysis throughout the design lifecycle is that it forms a complementary method for both user requirements specification early on and user-based testing at later stages. It is concluded that "an understanding of the Context of Use forms a useful input to the process of specifying usability requirements, constructing a design prototype which can be evaluated and evaluating the prototype with typical end-users" [Maguire, 2001:481].

Cramer et al [2004] discusses contextual analysis in VR applied to the case of a virtual radiology explorer (VRE) system aiding medical diagnosis and planning. This VRE prototype was developed in response to expressed needs from the medical world for research into VR visualisation and simulation of physiological properties. In this study it is stated that solutions for potential usability problems cannot be found without involvement of prospective end-users and more detailed knowledge about the VRE's context of use. Cramer concludes that "contextual analysis offered useful information to support development of the VRE” [Cramer et al, 2004:185].

Mills [2001] reports on the important role of task analysis as part of a usability context analysis to ensure fitness for purpose. The paper indicates, by using an example of an echosounder, that a task-based approach can highlight discrepancies of use. A recent article by the same author [Mills, 2007: 499] again stresses the fact that "studies involving a critical assessment of usability context analysis within the software domain are scarce”.

\section{METHODOLOGY}

Data collection was done in an integrated fashion addressing several of the context-of-use issues in each data collection instrument or session. The methods used were:

- Semi-structured interviews with mine managers and safety, health and environment (SHE) managers.

- $\quad$ Structured interviews with mine workers.

- Observations of current training methods at different mines.

- Questionnaires completed by trainees on specific context-of-use issues.

- $\quad$ Observations were carried out at several underground mining stope areas to observe the miners performing their daily tasks.

- $\quad$ Online questionnaires completed by 223 trainees after completion of the prototype training system.

Some of the enquiry methods were used at an early stage to investigate the environment and the target group, while the questionnaires addressed general contextual issues that emerged from use of the prototype.

The researcher carried out observations in an unobtrusive manner. The participants were observed while they were working underground. Questions were asked to verify the information gathered during the interviews before or after work activities. Photographs and video material were taken whenever possible and where permissible. Triangulation was used to synthesize the data collected from multiple sources.

Context-of-use analysis can be conducted in different ways. Some researchers take the contextual decisions without collecting or analysing data. Others investigate approaches as they evolve, as did Hay, Kim and Roy [2005], who used constructivist VR technology to support first-level astronomy students in learning about the solar system. In the present study the approach was to conduct some of the context analysis prior to the design of technological interventions, but also to obtain further data later by studying a prototypical VR system in its environment of use.

In support of the findings of the context-of-use analysis for mine safety training, a virtual reality interactive training system was designed and developed. This prototype training system focuses on hazard recognition and remedial actions training in conventional mining and is called Look, Stop and Fix. The prototype simulates the underground working areas, incorporating potential hazards that mine workers need to identify, as well as indicating the appropriate actions to be followed in response to each hazard. Trainees have to spot potentially hazardous conditions, identify the hazards correctly and indicate which actions should be taken to address the situation. Failure to correctly identify a hazard or to specify the correct action in dealing with such a hazard causes an animation to play out displaying the possible disastrous consequences of ignoring or incorrectly responding to such a hazard.

\section{FINDINGS}

The first research question of this study aimed to investigate the contextual requirements and constraints for VR training systems for the mining industry. As indicated in Figure 2, the major context-of-use issues are users, tasks, equipment and environment. The findings are presented under these headings.

\subsection{Users}

The Department of Minerals and Energy uses the Mining Industry Standard Code of Occupations [Department of Minerals and Energy, 2008], listing 1032 job titles in the mining profession. For the purpose of this study only underground mine workers were observed and interviewed, involving mainly the following jobs: Belt Attendant, Miner, Cheesa (Miner's assistant), Rock Drill Operator, Loco Driver, Panel Operator, Shift Supervisor, Team Leader, Stope Timberman and Winch Operator.

A total of 43 structured interviews were conducted with randomly selected workers from 10 Shaft at Impala Platinum Mine. The interviews were conducted by clerks from 10 Shaft in the workers' preferred language and the interviewees' answers were written down on a prepared interview sheet. Analysis of the interview answers yielded the following results:

- The subjects have different cultural backgrounds and speak various languages.

- $\quad$ Some have a very limited understanding of English.

- $\quad$ Ages are between 20 and 60; levels of education vary from Grade 5 to Grade 12. 
- $\quad$ The interviewees have various levels of underground mining experience, ranging between 2 years and 25 years.

- Currently, most underground workers are men, but some mines are appointing women in certain of these job positions.

- The majority of the interviewees are confident that they can perform their duties well.

- More than $80 \%$ of the interviewees have never used a computer.

- To determine usage of technology, workers were asked whether they use cell phones and ATM's. More than $80 \%$ answered in the affirmative. Despite their wide range in literacy level and minimal computing experience, they were not afraid of the prospect of computer-based training. In fact, they were of the opinion that they would enjoy it!

It also emerged from the interviews that workers are concerned about safety and the high number of accidents in the industry. The researcher noted that the National Union of Mineworkers organised a formal protest march in December 2007 where thousands of mineworkers marched in central Johannesburg, urging management to improve safety conditions. Concern is also raised with regard to production bonuses offered by certain mines, which might place the emphasis on production at the potential cost of safety.

\subsection{Tasks}

Many varying tasks of different categories of underground workers were identified in observation and in discussions with SHE managers and workers. For the purpose of this study it was decided to focus on hazard recognition, identification and correct procedures in addressing hazards. All underground workers should be aware of hazards in the workplace, both in the haulage and in the stope area.

Hazards can be classified as generic or job-specific. All underground workers should be able to identify and fix generic hazards, while job-specific hazards refer to potentially dangerous conditions that can occur while performing duties of a specific job. For example, a winch operator may encounter various hazardous conditions while working with the winch which the rock drill operator may not be exposed to, but since the winch cables and snatch blocks are used within the stope area there are some generic winch hazards which all workers should be aware of.

Analysis of the data obtained via interviews and observation led to the categorisation of generic hazards into five groups: Employee actions, Geological conditions, Machinery and equipment, Good house-keeping and Sub-standard conditions. For each of these task groups, workers should be able to recognise particular hazards, correctly identify them and follow the correct procedure in dealing with them.

\subsection{Equipment}

The researcher noted that the equipment used by workers depends on their particular duties. For example, a cheesa might use a pinch bar to make an underground workplace safe by means of barring down loose rocks, whereas the rock drill operator uses a pneumatic or hydraulic rock drill. It was mentioned by SHE managers that specialised training is required for using different tools and equipment.

Workers are required to wear the correct PPE (Personal Protective Equipment), which usually includes a hard hat, overall, boots, ear plugs, cap lamp, battery pack and protective glasses. Not wearing the correct PPE is also a generic hazard.

\subsection{Work environment}

Based on observations, the underground work environment can be described as dirty, dark, wet, noisy, hot, uncomfortable and dangerous. Hazards related to the work environment can include:

- Working in confined areas.

- Working in steeply inclined excavations.

- Handling heavy material and equipment.

- Working in the proximity of moving machinery.

The size of the stope areas, where drilling and blasting occur, varies from one mine to another, but the stopes observed were approximately 27 meters wide with a maximum height of 1.5 meters. The gulley area next to the stope, from which the scraper winch extracts the blasted rock, is about 2.5 meters high, allowing workers to stand upright when not working in the stope. Rock drill operators work in a sitting position while drilling holes for the explosives. Blasted areas are watered down as part of the cleaning process, causing the areas to wet. Excessive water is hazardous and can lead to slip-and-fall incidents.

With ground falls being the main cause of fatalities in the industry, it is essential to correctly identify different geological conditions, especially after blasting. Conditions such as shear zones, joints and dykes should be supported correctly to prevent falls of ground, and loose rocks should be barred off. A significant proportion of rockfall accidents occur during re-entry after blasting, when the initial inspection and making-safe procedures are conducted to stabilise the rock before work recommences.

Generic workplace hazards generally relate to support conditions, ground conditions, inadequate escape ways or obstructions in escape ways, fire, exposure to unsafe electrical connections, humans in proximity of the area where loose rocks are to be barred, and working under unsafe roofs or sidewalls. These findings were corroborated by data collected from interviews with safety and health managers.

\subsection{Training environment and organisational aspects}

Training is done in accordance with the unit standards as specified by the Mining Qualifications Authority. Most mines have training centres where new recruits are trained in jobrelated courses. This training is predominantly instructor-led and occurs in a class-based environment. In general, the use of technology in training is limited, but some mines do have computer-based training facilities. Class room training is usually followed up by practical training in the real work environment, until the instructor certifies the trainee as competent to perform the work correctly and safely.

Workers returning from annual leave, so called ex-leaves, go to the training centre for refresher courses before being permitted 
in the underground milieu. A factor of concern noted by the researcher is the lack of assessment after these refresher courses for ex-leaves. Sometimes workers merely sign a form indicating that they have worked through the files.

The issues identified in this integrated data collection process posed a challenge to the researcher in his role as potential designer of a VR prototype for focused training to address the problems related to hazards.

\section{THE LOOK, STOP AND FIX PROTOTYPE}

It emerged from interviews with mine managers that improved and technologically advanced training systems are required to assist them to improve the safety records at their mines. With this in mind it was decided to develop a non-immersive VR prototype focusing on generic hazards.

The context-of-use analysis provided valuable information to inform the design of the prototype. Based on this information it was decided that trainees would be placed in a $3 \mathrm{D}$ virtual underground environment, where the haulage and stope areas would be realistically simulated. Various generic hazards would be present in this environment, selected randomly from the five categories of hazards generated from the analyses as discussed in 6.2 (see Table 1).

Table 1. Generic hazards included in the prototype.

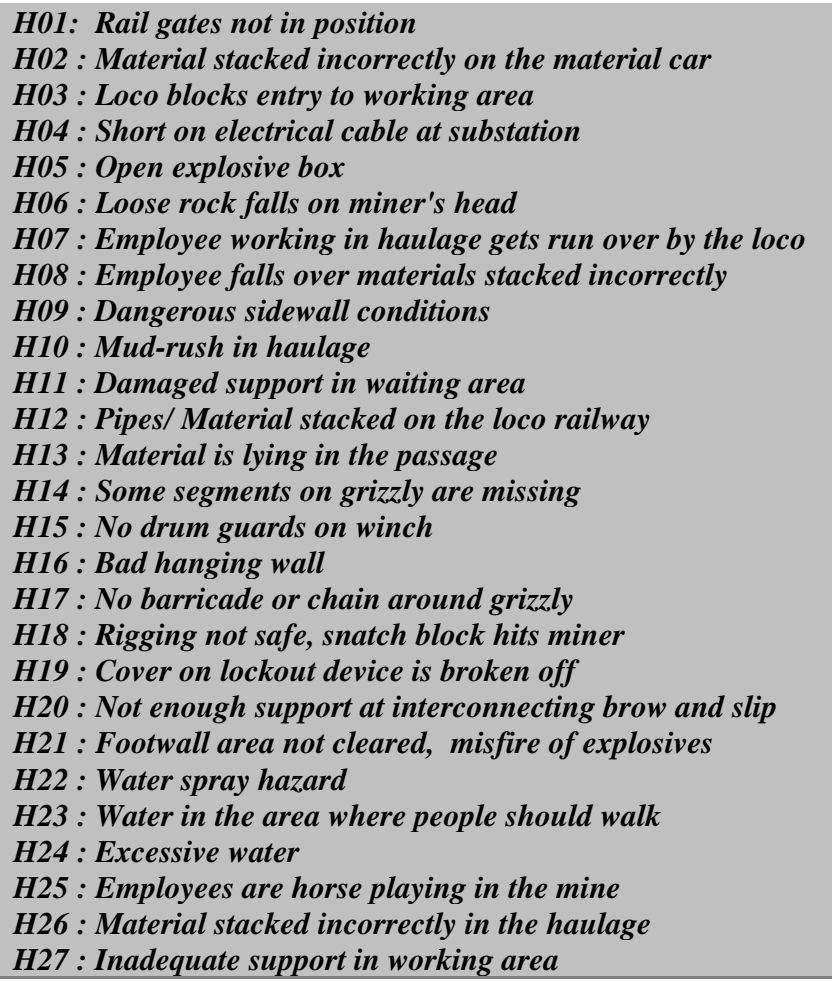

In the Look, Stop and Fix prototype a camera pans slowly through the 'mine'. On the bottom of the screen a STOP button and a REPLAY button are visible. At any point in time, while the camera is moving through the mine, the user can use the mouse to click on any of the buttons. If the user clicks on
REPLAY, the previous scene is replayed and the user has another opportunity to view the environment. If the user clicks on STOP, the camera stops and two other buttons appear, GO and IDENTIFY. Figure 3 is a screenshot taken from the prototype. (Note: The screenshots in Figures 3, 4 and 5 may appear dark. This is an accurate reflection of the actual underground work environment and the VR prototype was developed to portray realism).

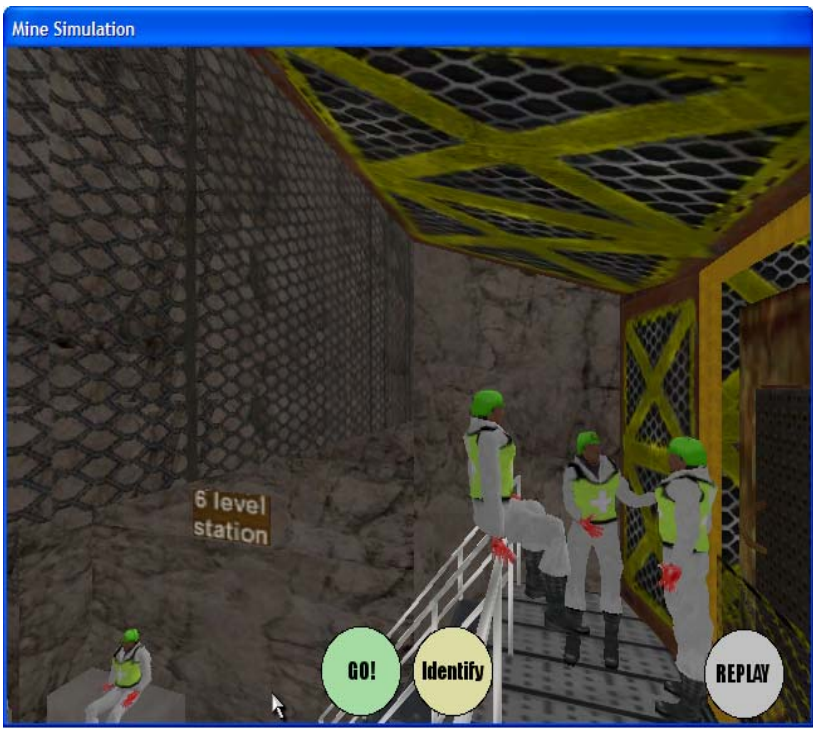

Figure 3. Screenshot of available options when user has stopped the simulation.

If the user is of the opinion that there is a hazard then the IDENTIFY button should be clicked. If not, clicking on GO will continue with the simulation. If a hazard is present and the user clicked on IDENTIFY, then a number of possible hazards are shown and the user should select the appropriate one (see Figure 4). In the case of the correct hazard being selected, then a number of remedial actions are shown and the user should select the correct action.

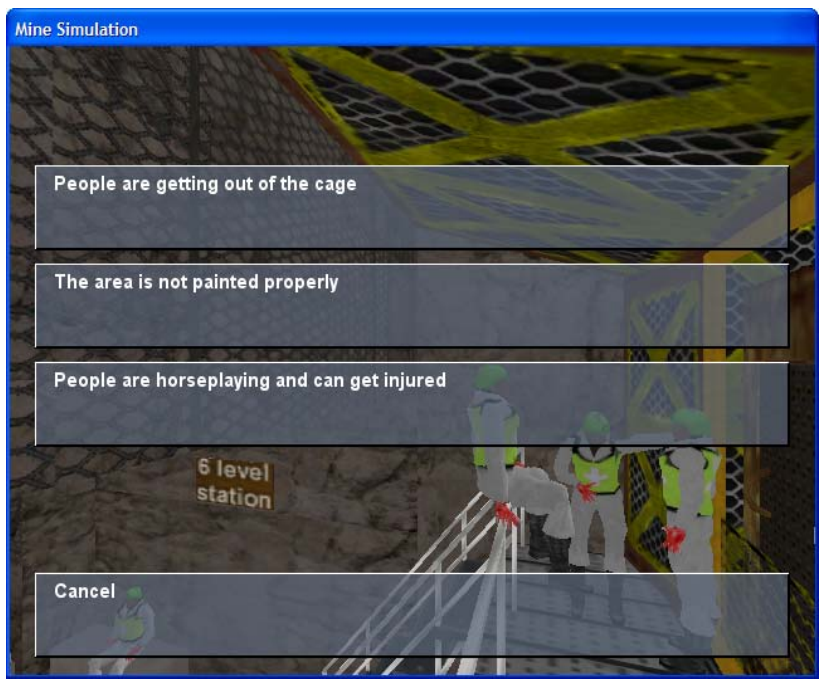

Figure 4. Example screen shot of options the user can select when identifying a hazard. 
The simulation is in the form of a game and participants receive a score for each correctly identified hazard as well as for correctly indicating the procedure to deal with each hazard. Different types of hazards have different score values. If they do not correctly identify a hazard or the correct procedure for dealing with such a hazard, an animation plays out displaying the possible disastrous consequences of ignoring such a hazard (see Figure 5).

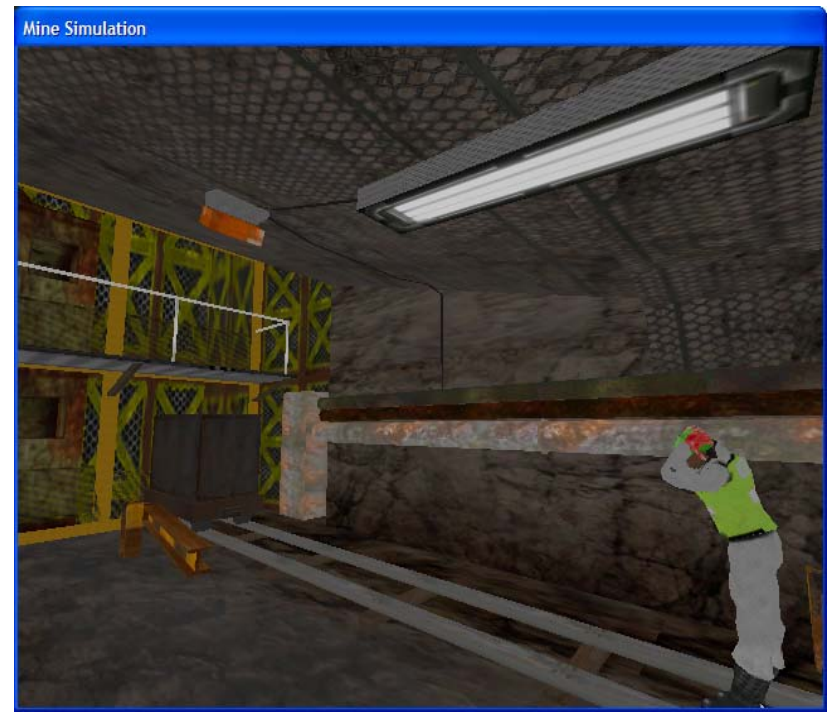

Figure 5. Animation of potential consequence of not closing the rail gate.

In the Look, Stop and Fix prototype users select their language of choice for use in the system. The options are English, Tswana, Sepedi and Xhosa. In the software the selected language is used throughout the simulation for any textual feedback. Participants can also hear the text in this language in audio mode via their earphones when the computer mouse cursor moves over the written text. Participants also receive feedback and explanations in the selected language.

\section{PRACTICAL IMPLICATIONS}

\subsection{Usability evaluation}

Usability testing of a product is an approach that emphasizes the property of being usable, where the product is tested rather than the user [Preece, Rogers and Sharp, 2007]. The usability testing of Look, Stop and Fix involved a combination of user tests and user satisfaction questionnaires. The user tests measured user performance on hazard awareness tasks in the prototype system.

Since most trainees had not used a computer before, a pretraining programme was developed. This programme utilises videos and practice exercises to ensure that participants master the required computer literacy skills. Four exercises were included in the programme to enable the trainee to develop these skills:

- "Drag and Drop".

- "Click" (choice and movement of cursor).

- "Movie clips” visual introduction to PC and keyboard functions.

- "Catch the rock" game to improve hand eye coordination.
We were pleasantly surprised by the speed with which the participants mastered the pre-training. The pre-training software proved to be particularly effective for this purpose. This can also be ascribed to the fact that most / many of them use cell phones and / or bank ATM cards.

Upon successful completion of the pre-training exercises the participants logged onto the Look, Stop and Fix VR prototype using their employee numbers. They then selected the language they preferred to use in the system.

In the prototype participants received marks for three actions: correctly spotting a hazard, correctly identifying the hazard and for taking the correct action in dealing with such a hazard. The letters S (spot), I (identify) and F (fix hazard) were used to indicate results. After completion of the training, the system showed results in terms of $\mathrm{S}$, I and F values, a final percentage, performance on each hazard (numbered H01 to H27), as well as the number of guesses (clicks on the IDENTIFY button when there is no hazard present). The pass mark was $80 \%$. Most of those who did not pass had another attempt at working through the system. The average score achieved by the 223 workers was $73 \%$. This average reflected the scores of all the first attempts. The average achieved for second attempts was $79 \%$.

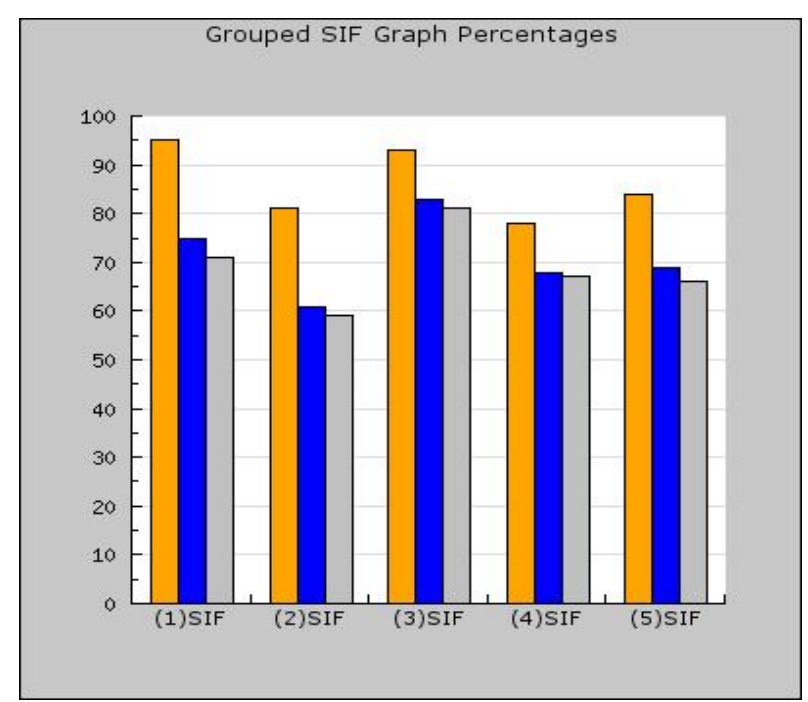

Figure 6: Spot, Identify and Fix percentages achieved per hazard group on first attempts

Figure 6 indicates the user performance related to the five hazard groups. The identification of hazards correctly spotted in Group 2 hazards (Geological conditions) proved to be more problematic than the other groups. Regarding identifying and fixing hazards, the participants performed best in identifying and fixing Group 3 hazards (Good house-keeping). Trainees only spotted $78 \%$ of Group 4 hazards (Machinery and equipment), the lowest of the four groups. Group 1 hazards (Unsafe acts by employees) were spotted the best, but there was a 20\% gap between hazards spotted and hazards correctly identified. In all five groups there was a very small difference between the number of hazards identified and the correct actions specified. 
To evaluate user satisfaction of the prototype, an online questionnaire was completed by each of the participants after completion of the prototype training. This yielded the following major results:

- $87 \%$ of the participants indicated that they could easily identify all the objects in the simulated environment (high visibility).

- $\quad 93 \%$ found the system easy to use and understand (learnability and ease of use).

- $95 \%$ indicated that using the prototype was an enjoyable experience (user satisfaction).

- $\quad 84 \%$ indicated that they would prefer VR training to other types of training (method of choice).

The participants were also asked whether they thought the hazards included in the prototype system (authenticity) could really happen. Most participants felt that all the hazards portrayed were real hazards in their working environment. It is interesting to note that in a follow-up question as to whether the accidents in the system could actually happen to them, many thought most of them would not. This could be that certain hazards would not be a threat to them in their particular jobs, but it could also be an indication of a lax attitude that accidents are more likely to happen to others than to themselves.

\subsection{Virtual Reality environments}

The second research question aimed to determine what type of VR environment would be most suitable for mine safety training. To accommodate high volumes of trainees, the use of non-immersive systems on ordinary personal computers can provide a means of achieving current training goals. It is expected that as the technology gradually matures in this industry, facilities will be provided for more individualised systems to be developed and implemented, especially for training in the use of very expensive equipment such as the continuous miner or drill rigs.

Because work underground is performed in teams, it also becomes imperative to provide a simulated training environment in which the team can work together as a unit. Semi-immersive systems using stereoscopic projection or immersive systems can cater for this need.

Stereoscopic panoramic environments can be used to immerse an audience in 3D imagery. Such a system could include a vision-based motion tracking system capable of tracking and responding to movements of users. Stereoscopic projection onto a dome structure can also be used for spherical representations to cover the peripheral vision of a user standing directly in front of it. This can result in a truly immersive experience. Stereoscopic glasses allow the simulations to be seen in 3D and panoramic screen projection enables a group of miners to experience simulations with an incredible degree of realism. Trainees can be confronted with high-fidelity representations of real-world problems.

\subsection{Virtual Reality suitability and potential}

The third research question addressed the general suitability and potential of VR technology for training applications in mine safety. Sophisticated technology (such as VR simulations) for the training of highly skilled equipment operators has never been available in the South African Mining Industry to train ordinary employees (not to mention the illiterate).

Although there is increased acceptance of the enormous changes in technology and its use, it is clear that the usual mine worker is very far removed from these technological advances. They are aware of them but they have very little-to-no opportunity of experiencing sophisticated technology and its benefits directly. Most of them have never touched a computer in their lives.

A further implication of successfully introducing this technology to the mining industry is the possibility of developing job-specific training systems. Trainees will be able to practise the tasks to be executed with specific equipment or tools in a simulated environment. This would ideally be achieved in a more immersive virtual environment such as wearing headsets and data gloves. The drawback of this is the potentially high cost of the VR equipment and development of these systems as well as the fact that the immersive environment will be highly individualised. Currently there are more than 200 000 miners working underground in South African mines on a daily basis, stressing the need for training systems capable of accommodating high volumes of trainees.

The VR Interactive training system achieved the following objectives:

- Introduced higher technology (VR) with the focus on safety. This ensures that the workforce has a high level of competence before entering the real environment.

- Introduced the format of interactivity (participation) in learning material.

- Deficiencies in training can be identified without risk, as high-risk scenarios are simulated in a safe and controlled environment. Working in such simulated environments increases the realism of the training experience, allows high cost equipment to remain in production and assists trainers in identifying unsafe practices performed by trainees.

- Demonstrated a level of usability that engrossed its target audience, despite their general low level of computer literacy.

- $\quad$ Proved to be a successful bridge of the gap between illiteracy and higher levels of training with multimedia/visual conceptual learning. Literacy level is still a significant problem which is significantly addressed by 3D animated and multimedia effects.

- The introduction of a choice of sound and language. A trainee can adjust his own volume to a required level, plus he can select his language of choice to listen to all prompts and commands.

- Trainees clearly showed the variance in speed of learning which is well accommodated in the VR safety programme. Pace of interpreting the learning programme becomes individualized, because the employee is not subjected to the pace of the instructor or other trainees.

- The excitement of the participants as they began to engage with the learning experience after the realisation that they had managed to conquer the technology. 
Once the users realise that the "machine" is very friendly and even "talks" to them in the language of their choice, they start to relax. The sense of achievement once they have mastered the new training tool is enormous and is reflected in their response at the end of the training period. The emphasis was to introduce the system without the fear of failure.

\section{CONCLUSION}

The introduction of the interactive simulation training system has been beneficial to the workforce. No statistical data is yet available to prove that the accident rate has been reduced. That will require extensive use of such systems and several years of data collection and analysis. The VR prototype system was well received and provided an interesting and enjoyable alternative to other training programs, while at the same time it also improved the safety culture and awareness of the workforce.

Future work will focus on the introduction of training systems that are more immersive, as well as the development of a usability evaluation framework for such systems. There is also scope for extending the development of interactive simulation training systems beyond the generic hazard awareness systems to several other training milieus, such as trackless moving machinery pre-inspections, smelting plant safety aspects, accident reconstruction simulations, isolation procedures, systematic supervision, conveyor procedures and winch operations.

\section{ACKNOWLEDGEMENTS}

We would like to thank all the participants in this study. We appreciate the invaluable help of the mine managers and SHE managers for participating in personal interviews. The expertise of the students at the Centre for Creative Technologies at TUT, who developed the prototype, is gratefully acknowledged.

\section{REFERENCES}

[1] Baker, D. 2005. Interview with Safety, Health and Environment Manager, Anglo Platinum BafokengRasimone. (Notes in possession of author).

[2] Brooke, J. 1998. System Usability Scale. Online: www.usabilitynet.org/trump/documents/Suschapt.doc. [Accessed: 12/05/2008].

[3] Bevan, N. 1997. Usability Context Analysis: a Practical Guide. NPL Usability Services, Teddington, UK.

[4] Business Day, 2002. Union seeks an audit of Mine Safety [Online]. Available from: http://www.bullion.org.za/DailyMiningNews/2004notd/Fe b/050204.htm. [Accessed: 12/06/2007].

[5] Chamber of Mines of South Africa, 2004. Department of Mineral and Energy Affairs. Annual Report 2004.

[6] Cramer, H.S.M., Evers, V., Zudilova, V. and Sloot, P.M.A. 2004. Context analysis to support development of virtual reality applications. Virtual Reality 7: 177-186

[7] De Strulle, A. 2004. Differentiation of the Causal Characteristics and Influences of Virtual Reality and the Effects on Learning at a Science Exhibit. PhD Thesis. University of San Diego.
[8] Department of Minerals and Energy, 2006. Guideline for Enforcement of the Mine Health and Safety Act [Online]. Available from: http://www.dme.gov.za/publications/pdf/guidelines/guidel ine_enforcement_mhs_act.pdf. [Accessed: 22/12/2006].

[9] Department of Minerals and Energy, 2007. Accident Statistics [Online]. Available from: http://www.dme.gov.za/mhs/accident_stats.stm. [Accessed: 20/07/2007].

[10] Department of Minerals and Energy, 2008. SAMRASS [Online]. Available from: http://www.dme.gov.za/pdfs/mhs/samrass/cb_sect_e.pdf. [Accessed: 16/06/2008].

[11] Hay, K., Kim, B., and Roy, T. C. 2005. Design-Based Research: More than Formative Assessment? An Account of the Virtual Solar System Project. Educational Technology 45(1): 34-41.

[12] ISO. 1997. ISO 9241-11: Ergonomic requirements for office work with visual display terminals (VDT'1s). Part 11 guidelines for specifying and measuring usability. Geneva: International Standards Organisation.

[13] ISO. 1999. ISO 13407: Human-centred design processes for interactive systems. Geneva: International Standards Organisation.

[14] Lubbe, O.S. 2006. Interview with Chief Executive, Chrome Mining Division, XSTRATA Alloys, Rustenburg, (notes in possession of the researcher).

[15] Maguire, M. 2001. Context of Use within usability activities. International Journal of Human-Computer Studies 55, 453-483

[16] Mills, S. 2001. The importance of task analysis in Usability Context Analysis - designing for fitness for purpose. Behaviour \& Information Technology, Vol. 19, no $1,57-68$

[17] Mills, S. 2007. Contextualising Design: Aspects of using usability context analysis and hierarchical task analysis for software design. Behaviour \& Information Technology, Vol. 26, No 6 Nov - Dec 2007, 499 - 506

[18] Mining Weekly, 2002. Mine health and safety on the road to recovery [Online]. Available from: http://www.miningweekly.co.za/min/features/health/?sho w=21234. Published: 2002/05/10. [Accessed: 12/06/2007]

[19] Moldenhauer, R. 2004. Interview with Safety, Health and Environment Manager, Anglo Platinum Lebowa, (notes in possession of the researcher).

[20] Orr, T.J., Filigenzi, M.T., and Ruff, T.M. 2002. Desktop Virtual Reality Miner Training Simulator [Online]. Available from: www.cdc.gov/niosh/mining/pubs/pdfs/dvrmt.pdf. [Accessed: 12/01/2007].

[21] Preece, J., Rogers, Y., and Sharp, H. 2007. Interaction Design - beyond human-computer interaction. John Wiley \& Sons.

[22] Squelch, A.P. 2000. VR as an industrial training and marketing tool. Conference Proceedings IFIP 2000 
[Online]. Available from: www.irv.ufsc.br/IFIP-WG9.5/proceedings. [Accessed: 12/04/2008].

[23] Stander, D. 2005. Interview with Mine Manager Anglo Platinum Lebowa, (notes in possession of the researcher).

[24] Van Wyk, E. 2006. Improving Mine Safety Training Using Interactive Simulations. In: Proceedings of the EDMEDIA 2006 World Conference on Educational Multimedia, Hypermedia and Telecommunications 2006: 2454-2459. Orlando, Florida.

[25] Wenhold, M. 2005. Interview with Safety, Health and Environment Manager, Impala Platinum Rustenburg. (Notes in possession of the researcher). 